\section{JURNAL EKONOMI EFEKTIF}

ISSN : $2622-8882$, E-ISSN : 2622-9935

Jurnal Ekonomi Efektif, Vol. 4, No. 1, Oktober 2021 @Prodi Manajemen Fakultas Ekonomi Universitas Pamulang

\title{
PENGARUH EXPERIENTAL MARKETING DAN BRAND IMAGE TERHADAP KEPUASAN KONSUMEN PADA EIGER STORE SORONG
}

\author{
Jumarni Muhammad Saleh ${ }^{1}$, Wisang Candra Bintari ${ }^{2 *}$, Muhammad Ali ${ }^{3}$ \\ Universitas Muhammadiyah, Sorong, Papua Barat, Indonesia \\ binaricandra@gmail.com*
}

\begin{abstract}
Manuskrip: Agustus -2021; Ditinjau: Agustus -2021; Diterima: September-2021; Online: Oktober-2021; Diterbitkan: Oktober-2021
\end{abstract}

\begin{abstract}
ABSTRAK
Penelitian ini bertujuan untuk mengetahui pengaruh experiential marketing dan brand image secara simultan terhadap kepuasan pelanggan di Eiger Store Sorong. Penelitian ini merupakan penelitian kuantitatif dengan pendekatan deskriptif korelasional. Populasi dalam penelitian ini adalah konsumen Toko Eiger Sorong. Teknik pengambilan sampel yang digunakan dalam penelitian ini adalah accidental sampling dengan jumlah sampel 67 konsumen. Teknik pengumpulan data berupa angket, wawancara, dokumentasi, dan observasi. Teknik analisis data yang digunakan adalah regresi linier berganda. Hasil penelitian menunjukkan bahwa terdapat pengaruh secara simultan Experiential Marketing dan Brand Image terhadap Kepuasan Pelanggan pada Eiger Store Sorong. Hal ini ditunjukkan dengan nilai F hitung sebesar 40,491 dan signifikansi $0,000<0,05$. Koefisien determinasi (R2) sebesar 0,561 atau $56,1 \%$.
\end{abstract}

\section{Kata Kunci: Experiential Marketing, Brand Image, Kepuasan Konsumen}

\begin{abstract}
This study aims to determine the effect of experiential marketing and brand image simultaneously on customer satisfaction at the Eiger Store Sorong. This research is a quantitative research with a descriptive correlational approach. The population in this study are consumers of the Eiger Sorong Store. The sampling technique used in this study was accidental sampling with a total sample of 67 consumers. Data collection techniques in the form of questionnaires, interviews, documentation, and observation. The data analysis technique used is multiple linear regression. The results showed that there was a simultaneous effect of Experiential Marketing and Brand Image on Customer Satisfaction at the Eiger Store Sorong. This is indicated by the calculated $F$ value of 40.491 and a significance of $0.000<0.05$. The coefficient of determination (R2) is 0.561 or $56.1 \%$.
\end{abstract}

Keywords: Experiential Marketing, Brand Image, Consumer Satisfaction 


\section{PENDAHULUAN}

PT. Eigerindo Multi Produk Industri atau yang dikenal sebagai Eiger merupakan salah satu perusahaan perlengakapan outdoor terbesar yaitu Produk Eiger, memiliki kelebihan dan ciri khas tersendiri dibandingkan dengan perlengkapan outdoor merek lain. PT. Eigerindo Multi Produk Industri telah memiliki memiliki 6 Toko Eiger Adventure, 18 ruang pamer, dan 88 counter tersebar di seluruh Indonesia termasuk berada di Sorong Papua Barat.

PT. Nuraini Jaya Papua (Eiger Store Sorong) sebagai official retailer Eiger di Sorong yang sudah bekerjasama dengan perusahaan PT. Eigerindo Multi Produk Industri dan sudah terdaftar sebagai agen resmi untuk produk Eiger dikota Sorong.

Konsumen saat ini sangat pemilih dalam pembelian suatu produk, kepuasan konsumen merupakan suatu salah satu hal yang harus di perhatikan oleh perusahaan dalam memenuhi keinginan konsumen sehingga perusahaan belomba-lomba dalam meningkatkan kualiatas produk agar dapat mempertahankan brand (merek) produk yang mereka miliki. Kepuasan konsumen merupakan salah satu hal yang memiliki peranan penting dalam bisnis. Setiap konsumen memiliki tingkat kepuasan yang berbeda-beda, sehingga Kepuasan adalah respon pemenuhan dari pelanggan (Kho, Dessy Prayogo, 2014).

Menurut (Tjiptono, 2012) kepuasan konsumen adalah situasi yang ditunjukkan oleh konsumen ketika mereka menyadari bahwa kebutuhan dan keinginannya sesuai dengan yang diharapkan serta terpenuhi secara baik. Kepuasan konsumen pada akhirnya akan menciptakan loyalitas pelanggan kepada perusahaan yang memberikan kualitas yang memuaskan mereka (Cintya, 2015), Sehingga untuk memenuhi kepuasan konsumen Eiger Store Sorong harus mempunyai strategi salah satunya adalah strategi experiental marketing.

Experiental marketing adalah sebuah konsep pemasaran yang bertujuan untuk membentuk pelanggan-pelanggan yang loyal dengan menyentuh emosi mereka dan memberikan suatu feeling yang positif terhadap produk dan jasa yang mereka konsumsi(Kartajaya, H., Indrio, B. D., \& Madyani, 2004). Lebih lanjutnya Schmitt menyebutkan bahwa experiential marketing fokus pada pengalaman konsumen, menganggap konsumsi sebagai sebuah pengalaman secara keseluruhan, memperlakukan konsumen sebagai makhluk yang rasional dan juga emosional (Soli Noni Cecilia Sinaga, Muchsiin Saggaf Shibab, 2013). Inti dari experiential marketing adalah untuk membangun hubungan yang langgeng dengan pelanggan melalui 5 aspek yaitu panca indera (sense), perasaan (feel), cara berpikir (think), kebiasaan (act) dan pertalian atau relasi (relate) (Arsjad, 2019). Dan pada akhirnya inti dari strategi Experiental Marketing adalah membangun hubungan yang langgeng dengan pelanggan (Lullulangi, 2014). Dengan adanya experiental marketing dapat mempromosikan produk yang ada pada Eiger Store Sorong dengan merek (Brand Image) yang sama.

Brand Image adalah representasi dari keseluruhan persepsi terhadap merek dan dibentuk dari informasi dan pengalaman masa lalu terhadap merek itu (Herliza \& Saputri, 2016). Menurut (Kotler, P., Armstrong, G., Saunders, J., \& Wong, 2003) , Merek adalah nama, istilah, tanda, lambang, atau desain, atau kombinasi dari semua ini yang memperlihatkan identitas produk dan jasa dari satu penjual atau sekelompok penjual dan membedakan produk itu dari produk pesaing, Brand image yang baik sangat penting dikelola karena hal ini merupakan persepsi dan preferensi konsumen terhadap jasa yang diberikan kepada konsumen(Purba, 2019), Dengan manfaat dari Brand Image yang dimiliki suatu produk, perusahaan dapat mengupayakan pemenuhan kebutuhan pelanggan atau bahkan melampaui harapan-harapannya mengenai produk yang akan 
dikonsumsinya (Syarif, 2010)

Penelitian ini sebelumnya telah dilakukan oleh (Dwiastuti, 2016) Universitas Medan Area, dengan judul Pengaruh Experiental Marketing dan Brand Image terhadap Kepuasan Pelanggan Indihome PT. Telkom Akses Medan. Dari Hasil penelitian menunjukan bahwa experiential marketing dan brand image secara simultan berpengaruh positif dan signifikan kepuasan pelanggan Indihome PT. Telkom Akses Medan.(Andrieani, 2016) Universitas Sanata Dharma Yogyakarta, dengan judul Pengaruh Experiental Maketing dan Brand Image Terhadap Minat Berkunjung Kembali (Studi Kasus pada Keraton Ngayogyakarta Hadiningrat). Berdasarkan penelitian tersebut menunjukan bahwa diantara lima dimensi experiential marketing, dimensi yang berpengaruh terhadap minat berkunjung kembali wisatawan nusantara mandiri adalah dimensi perasaan (feel) dan dimensi berhubungan atau keterkaitan (relate). Sedangkan dimensi rasa (sense), dimensi berpikir (think), dan dimensi sikap (act) tidak berpengaruh terhadap minat berkunjung kembali wisatawan nusantara mandiri. Dan untuk variabel brand image berpengaruh terhadap minat berkunjung kembali wisatawan nusantara mandiri. Perbedaan penelitian ini dengan dua penelitian tersebut yaitu selain dari lokasi dan objek penelitiannya.

\section{TINJAUAN PUSTAKA}

\section{Experiental Marketing}

Experiential Marketing berasal dari 2 kata yaitu Experiential dan Marketing. Experiential sendiri berasal dari kata experience yang berarti sebuah pengalaman. Sedangkan Marketing adalah sebagai proses dimana perusahaan menciptakan nilai bagi pelanggan dan membangun hubungan yang kuat dengan pelanggan dengan tujuan untuk menangkap nilai dari pelanggan sebagai imbalannya (Kotler, Philip; Armstrong, 2008).

Experiental Marketing adalah sebuah konsep pemasaran yang bertujuan untuk membentuk pelanggan-pelanggan yang loyal dengan menyentuh emosi mereka dan memberikan suatu feeling yang positif terhadap produk dan jasa yang mereka konsumsi (Kartajaya, 2004).

Adapun indikator-indikator yang mempengaruhi experiental marketing yaitu Sense (Rasa), Feel (Perasaan), Think (Berpikir), Act (Bertindak), Relate (Berhubungan).

\section{Brand Image}

Citra merek (brand image) menurut Sangadji dan (Sangadji, E.M., 2013) mengatakan bahwa citra merek dapat positif atau negatif, tergantung pada persepsi seseorang terhadap merek.. Adapun indikator-indikator yang mempengaruhi brand image yaitu Corporate Image (Citra pembuat), User Image (Citra Pemakai), Produk Image (Citra Produk).

\section{Kepuasan Konsumen}

(Kotler, 2007) menyatakan bahwa "Kepuasan adalah perasaan senang atau kecewa seseorang yang muncul setelah membandingkan kinerja (hasil) produk yang dipikirkan terhadap kinerja yang diharapkan”.

Adapun indicator - indikator yang mempengaruhi kepuasan konsumen yaitu Kesesuain Harapan, Minat Berkunjung Kembali dan Kesediaan.

\section{METODE PENELITIAN}

Metode penelitian yang digunakan dalam penelitian ini adalah penelitian deskriptif kuantitatif dan jenis pendekatan yang di gunakan dalam penelitian ini menggunakan penelitian korelasional. Penelitian deskriptif merupakan penelitian yang bertujuan untuk menjelaskan, meringkaskan kondisi, berbagai situasi, atau beberapa variabel menjadi obyek 
penelitian berdasarkan apa yang terjadi (Bungin, 2013).

Penelitian Korelasi atau korelasional adalah suatu penelitian untuk mengetahui hubungan antara dua variabel atau lebih tanpa ada upaya untuk mengetahui variabel tersebut sehingga tidak terdapat manipulasi variabel (Frankel, 2008).

Populasi dalam penelitian ini adalah Konsumen Eiger Store Sorong. Teknik pengambilan sampel yang digunakan dalam penelitian ini adalah accidental sampling dengan jumlah sampel sebanyak 67 konsumen. Teknik pengumpulan data berupa kuesioner, wawancara, dokumentasi, dan observasi. Teknik analisis data yang digunakan adalah regresi linier berganda dengan rumus slovin sebagai berikut :

$$
\begin{aligned}
& \mathrm{n}=\frac{\mathrm{N}}{1+\left(\mathrm{N} \mathrm{x} \mathrm{e}^{2}\right)} \\
& n=\frac{80}{1+\left(80 \times(0,05)^{2}\right)} \\
& n=\frac{80}{1+(80 \times 0,0025)} \\
& n=\frac{80}{1,2} \\
& n=66,67
\end{aligned}
$$

\section{HASIL PENELITIAN}

\section{Uji Regresi Linear Berganda}

Analisis regresi linier berganda digunakan untuk meramalkan keadaan (naik turunnya) variabel dependen, jika dua atau lebih variabel independen sebagai faktor prediktor dimanipulasi (dinaik turunkan nilainya).

Persamaan regresi linier berganda dapat dirumuskan sebagai berikut:

Dimana :

$$
y=a+\beta 1 x 1+\beta 2 \times 2+e
$$

$\mathrm{Y}=$ Kepuasan Konsumen

$\mathrm{A}=$ bilangan konstanta

\begin{tabular}{|c|c|c|c|c|c|c|c|c|c|c|c|}
\hline & & & & Coeff & cients $^{a}$ & & & & & & \\
\hline & & $\begin{array}{l}\text { Unstanc } \\
\text { Coeffi }\end{array}$ & $\begin{array}{l}\text { ardized } \\
\text { ients }\end{array}$ & $\begin{array}{l}\text { Standard } \\
\text { ized }\end{array}$ & $\mathrm{t}$ & Sig. & & rrelatio & & $\begin{array}{r}\text { Collin } \\
\text { Stati }\end{array}$ & $\begin{array}{l}\text { arity } \\
\text { tics }\end{array}$ \\
\hline & & B & $\begin{array}{l}\text { Std. } \\
\text { Error }\end{array}$ & Beta & & & $\begin{array}{l}\text { Zero- } \\
\text { order }\end{array}$ & $\begin{array}{c}\text { Partia } \\
1\end{array}$ & Part & $\begin{array}{c}\text { Tolera } \\
\text { nce }\end{array}$ & VIF \\
\hline & (Constant) & .053 & 2.436 & & .022 & .983 & & & & & \\
\hline 1 & $\begin{array}{l}\text { Experiental } \\
\text { Marketing (X1) }\end{array}$ & .323 & .100 & .389 & 3.214 & .002 & .693 & .373 & .266 & .468 & 2.135 \\
\hline & $\begin{array}{l}\text { Brand Image } \\
(\mathrm{X} 2)\end{array}$ & .485 & .141 & .417 & 3.446 & .001 & .700 & .396 & .285 & .468 & 2.135 \\
\hline
\end{tabular}

$\beta 1, \beta 2, \beta 3: \ldots$ koefesien regresi

$\mathrm{X} 1=$ Experiental Marketing

$\mathrm{X} 2=$ Brand Image

$\mathrm{e}=$ standard eror

Tabel 1 Uji Regresi Linier Berganda

Sumber : Data Primer Diolah (2020).

Berdasarkan data pengujian regresi linier berganda pada tabel di atas maka di peroleh persamaan regresi sebagai berikut :

$$
Y=0,053+0,323+0,485
$$




\section{Uji Parsial ( Uji T)}

Dasar keputusan pembelian dalam uji t diatas ialah :

a. Jika thitung $>t_{\text {tabel }}$ maka $\mathrm{H}_{1}$ diterima

b. Jika $t_{\text {hitung }}<\mathrm{t}_{\text {tabel }}$ maka $\mathrm{H}_{0}$ ditolak

Rumus Untuk Mencari Nilai T Tabel Ialah :

$\mathrm{t}_{\text {tabel }}=(\mathrm{a} / 2 ; \mathrm{n}-\mathrm{k}-1)$

$\mathrm{t}_{\text {tabel }}=(0,05 / 2 ; 67-2-1)$

$\mathrm{t}_{\text {tabel }}=(0,025 ; 64)$

$\mathrm{t}_{\text {tabel }}=$ angka 0,$025 ; 64$ kemudian lihat pada distribusi nilai $\mathrm{t}_{\text {tabel }}$ maka ditemukan nilai $t_{\text {tabel }}$ sebesar 1,99773 maka terdapat berdasarkan hasil regresi nilai $t_{\text {hitung }}(7,744)>$ $t_{\text {tabel }}(1,99773)$ maka terdapat nilai yang signifikan antara variabel independen (bebas) terhadap variabel dependen (terikat).

Tabel 2 Hasil analisis Uji T Variabel Experiental Marketing

\section{Coefficients $^{\mathrm{a}}$}

\begin{tabular}{|c|c|c|c|c|c|c|c|c|c|c|}
\hline \multirow[t]{2}{*}{ Model } & \multicolumn{2}{|c|}{$\begin{array}{l}\text { Unstandardized } \\
\text { Coefficients }\end{array}$} & $\begin{array}{l}\text { Standardized } \\
\text { Coefficients }\end{array}$ & \multirow[t]{2}{*}{$\mathrm{T}$} & \multirow[t]{2}{*}{ Sig. } & \multicolumn{3}{|c|}{ Correlations } & \multicolumn{2}{|c|}{$\begin{array}{c}\text { Collinearity } \\
\text { Statistics }\end{array}$} \\
\hline & $\mathrm{B}$ & Std. Error & Beta & & & $\begin{array}{l}\text { Zero- } \\
\text { order }\end{array}$ & $\begin{array}{c}\text { Partia } \\
1\end{array}$ & Part & $\begin{array}{c}\text { Tolera } \\
\text { nce }\end{array}$ & VIF \\
\hline $\begin{array}{ll} & \text { (Constant) } \\
1 & \begin{array}{l}\text { Experiental } \\
\text { Marketing } \\
(\mathrm{X} 1)\end{array} \\
\end{array}$ & 4.212 & 2.286 & .693 & 1.842 & .070 & .693 & .693 & .693 & 1.000 & 1.000 \\
\hline
\end{tabular}

a. Dependent Variable: Kepuasan Konsumen (Y)

Sumber : Data Primer Diolah (2020).

Berdasarkan tabel diatas bahwa Experiental Marketing $\left(\mathrm{X}_{1}\right)$ memiliki nilai signifikan 0,000, karena nilai signifikan lebih kecil dari $(0,05)$, maka terdapat nilai pengaruh signifikan antara Experiental Marketing

Rumus Untuk Mencari Nilai T Tabel Ialah :

$$
\begin{aligned}
\mathrm{t}_{\text {tabel }} & =(\mathrm{a} / 2 ; \mathrm{n}-\mathrm{k}-1) \\
\mathrm{t}_{\text {tabel }} & =(0,05 / 2 ; 67-2-1) \\
\mathrm{t}_{\text {tabel }} & =(0,025 ; 64)
\end{aligned}
$$

$\mathrm{t}_{\text {tabel }}=$ angka 0,$025 ; 64$ kemudian lihat pada distribusi nilai $\mathrm{t}_{\text {tabel }}$ maka ditemukan nilai $t_{\text {tabel }}$ sebesar 1,99773 maka terdapat berdasarkan hasil regresi nilai $t_{\text {hitung }}(7,910)>$ $t_{\text {tabel }}(1,99773)$ maka terdapat nilai yang signifikan antara variabel independen (bebas)

\begin{tabular}{|c|c|c|c|c|c|c|c|c|c|c|}
\hline \multirow[t]{2}{*}{ Model } & \multicolumn{2}{|c|}{$\begin{array}{l}\text { Unstandardized } \\
\text { Coefficients }\end{array}$} & \multirow{2}{*}{$\begin{array}{c}\begin{array}{c}\text { Standar } \\
\text { dized } \\
\text { Coeffici } \\
\text { ents }\end{array} \\
\text { Beta }\end{array}$} & \multirow[t]{2}{*}{$\mathrm{T}$} & \multirow[t]{2}{*}{ Sig. } & \multicolumn{3}{|c|}{ Correlations } & \multicolumn{2}{|c|}{$\begin{array}{c}\text { Collinearity } \\
\text { Statistics }\end{array}$} \\
\hline & B & $\begin{array}{l}\text { Std. } \\
\text { Error }\end{array}$ & & & & $\begin{array}{l}\text { Zero- } \\
\text { order }\end{array}$ & $\begin{array}{c}\text { Parti } \\
\text { al }\end{array}$ & Part & $\begin{array}{l}\text { Toler } \\
\text { ance }\end{array}$ & VIF \\
\hline $\begin{array}{ll} & \text { (Constant) } \\
1 & \begin{array}{l}\text { Brand } \\
\text { Image } \\
(\mathrm{X} 2)\end{array}\end{array}$ & 1.827 & 2.537 & .700 & $\begin{array}{r}.720 \\
7.91 \\
0\end{array}$ & $\begin{array}{l}.474 \\
.000\end{array}$ & .700 & .700 & .700 & 1.000 & $\begin{array}{r}1.00 \\
0\end{array}$ \\
\hline
\end{tabular}
terhadap variabel dependen (terikat).

Tabel 3 Hasil analisis Uji T Variabel Brand Image

a. Dependent Variable: Kepuasan Konsumen (Y)

Sumber : Data Primer Diolah (2020).

Berdasarkan tabel diatas bahwa Brand Image $\left(\mathrm{X}_{2}\right)$ memiliki nilai signifikan 0,000, karena nilai signifikan lebih kecil dari $(0,05)$, maka terdapat nilai pengaruh signifikan antara Brand Image $\left(\mathrm{X}_{2}\right)$ terhadap Kepuasan Konsumen (Y). 


\section{Uji Simultan (Uji F)}

Uji F di gunakan untuk mengetahui apakah semua variabel independen mempunyai pengaruh secara bersama-sama terhadap variabel dependen.

Tabel 4 Hasil Uji F

\begin{tabular}{|rl|r|r|r|r|r|}
\hline Model & & Sum of Squares & Df & Mean Square & F & Sig. \\
\hline \multirow{3}{*}{1} & Regression & 550.970 & 2 & 275.485 & 40.941 & $.000^{\mathrm{b}}$ \\
& Residual & 430.642 & 64 & 6.729 & & \\
& Total & 981.612 & 66 & & & \\
\hline
\end{tabular}

a. Dependent Variable: Kepuasan Konsumen (Y)

b. Predictors: (Constant), Brand Image (X2), Experiental Marketing (X1)

Sumber : Data Primer di olah (2020)

Dari hasil pengujian di atas maka dapat di simpulkan dalam Uji Simultan (uji F) pada hipotesis ketiga adalah $\mathrm{F}$ hitung sebesar 40,491 > t tabel sebesar 3,14 dengan signifikansi $0,000<$ dari taraf signifikansi yaitu 0,05 , artinya menunjukkan $\mathrm{H}_{3}$ di terima dan $\mathrm{H}_{0}$ di tolak, sehingga variabel Experiental Marketing $\left(\mathrm{X}_{1}\right)$ dan variabel Brand Image $\left(\mathrm{X}_{2}\right)$ secara bersama-sama (simultan) berpengaruh terhadap Kepuasan Konsumen (Y).

\section{Koefisien Determinasi $\left(\mathbf{R}^{2}\right)$}

Koefisien determinasi di gunakan untuk mengetahui seberapa besarnya persentase hubungan variabel independen terhadap variabel dependen.

Tabel 5 Hasil Analisis Koefisien Determinasi

Model Summary ${ }^{b}$

\begin{tabular}{|l|l|l|l|l|}
\hline Model & R & R Square & Adjusted R Square & $\begin{array}{l}\text { Std. Error of the } \\
\text { Estimate }\end{array}$ \\
\hline 1 & $.749^{\mathrm{a}}$ & .561 & .548 & 2.594 \\
\hline
\end{tabular}

a. Predictors: (Constant), Brand Image (X2), Experiental Marketing (X1)

b. Dependent Variable: Kepuasan Konsumen (Y)

Sumber : Data Primer Di olah (2020)

Berdasarkan tabel di atas di ketahui nilai koefisien determinasi (R square) sebesar 0,561, besarnya angka koefisien determinasi sama dengan 56,1\%. Angka tersebut mengandung arti bahwa Experiental Marketing dan Brand Image berpengaruh terhadap Kepuasan Konsumen. Sedangkan sisanya 43,9\% (100\% - 56,1\%) di pengaruhi oleh variabel lain di luar dari variabel penelitian

\section{KESIMPULAN DAN SARAN}

\section{Kesimpulan}

Berdasarkan hasil penelitian dan pembahasan, maka dapat ditarik beberapa bagai berikut:

a. Experiental Marketing berpengaruh positif secara parsial terhadap Kepuasan Konsumen pada Eiger Store Sorong. Hal ini dibuktikan dari nikai t hitung sebesar 7,744, nilai signifikan $0,000<0,05$ dan koefisien regresi sebesar 0,323

b. Brand Image berpengaruh positif secara parsial terhadap Kepuasan Konsumen pada Eiger Store Sorong. Hal ini dibuktikan dari nikai t hitung sebesar 7,910, nilai signifikan $0,000<0,05$ dan koefisien regresi sebesar 0,485

c. Experiental Marketing dan Brand Image berpengaruh secara simultan terhadap Kepuasan Konsumen pada Eiger Store Sorong. Hal ini di buktikan dengan nilai F hitung sebesar 40,941, dengan signifikansi 0,000<0,05.

d. Koefisien determinasi $\left(\mathrm{R}^{2}\right)$ sebesar 0,561, artinya 56,1\% Kepuasan Konsumen dapat dijelaskan oleh variabel Experiental Marketing dan Brand Image. Sedangkan sisanya 43,9\% dipengaruhi oleh variabel lain yang tidak diteliti dalam peelitian ini. 


\section{Saran}

a. Variabel Experiental Marketing berpengaruh secara positif dan signifikan terhadap Kepuasan Konsumen. Berdasarkan hasil penelitian variabel experiental marketing ditemukan bahwa masing-masing total skor indikator yaitu :

1) Sense (Panca Indera)

Sense (Panca Indera) dengan total skor (566), dimana indikator sense (Panca Indera) memperoleh nilai yang paling tinggi sehingga harus di pertahankan.

2) Feel (Perasaan).

Feel (Perasaan) dengan total skor ( 516), dimana indikator feel (perasaan) memperoleh nilai paling tinggi sehingga harus di pertahankan.

3) Think (Berpikir)

Think (Berpikir) dengan total skor (499), dimana indikator think (berpikir) memperoleh nilai yang tidak terlalu tinggi atau sedang sehingga harus diperbaiki dan ditingkatkan lagi.

4) Act (Tindakan)

Act (Tindakan) dengan total skor (460), dimana indikator act (tindakan) memperoleh nilai paling rendah sehingga harus diperbaiki dan dievaluasi lagi.

b. Variabel Brand Image berpengaruh secara positif dan signifikan terhadap kepuasan konsumen. Berdasarkan hasil penelitian variabel brand image ditemukan bahwa masing-masing total skor indikator yaitu :

1) Corporate Image (Citra Pembuat)

Corporate Image (Citra Pembuat) dengan total skor (577), dimana indikator Corporate Image (Citra Pembuat) memperoleh nilai yang paling tinggi sehingga harus di pertahankan.

2) User Image (citra pemakai)

User Image (citra pembuat) dengan total skor (529), dimana indikator user image (citra pembuat) memperoleh nilai yang rendah sehingga harus dipebaiki.

3) Produk Image (Citra Produk)

Produk Image (Citra Produk) dengan total skor (548), dimana indikator Produk Image (Citra Produk) memperoleh nilai yang tidak terlalu tinggi atau sedang sehingga harus ditingkatkan lagi.

c. Bagi Peneliti Selanjutnya

Mengingat besarnya proporsi variabel Experiental Marketing (X1) dan Brand Image (X2) terhadap variabel Kepuasan Konsumen dilihat dari Koefisien Determinasi $\left(\mathrm{R}^{2}\right)$ menunjukan angka Adjusted $R$ Square sebesar $54,8 \%$ dan sisanya masih $43,9 \%$ variabel bebas yang tidak diteliti dalam penelitian ini, maka peneliti menyarakan untuk peneliti selanjutnya diharapkan dapat mengembangkan variabel bebas yang belum diteliti.

\section{DAFTAR PUSTAKA}

Andrieani, A. (2016). Pengaruh Experiental Marketing dan Brand Image Terhadap Minat Berkunjung Kembali ( Studi Kasus Pada Keraton Ngayogyakarta Hadiningrat). Universitas Sanata Dharma Yogyakarta.

Ardani, W., Rahyuda, K., Giantari, I. G. A. K., \& Sukaatmadja, I. P. G. (2019). Customer satisfaction and behavioral intentions in tourism: A literature review. International Journal of Applied Business and International Management (IJABIM), 4(3), 84-93.

Arsjad, M. P. (2019). Pengaruh Experiential Marketing, Kualitas Pelayanan Dan Driver At 
Asih, P. S., et al. 2021). Analisis Faktor-Faktor Yang Mempengaruhi Keputusan Pembelian Produk Fastfood KFC Di Kota Sorong (Studi Kasus Mega Mall Kota Sorong). Jurnal Ilmiah PERKUSI, 1(3), 352-356.

Cintya, D. (2015). Pengaruh Kualitas Produk dan Brand Image Terhadap Loyalitas Pelanggan Dengan Kepuasan Konsumen Sebagai Variabel Intervening (Studi Pada Konsumen Produk "Supermi” di Kecamatan Genuk Semarang). Skripsi, 106.

Dwiastuti, A. L. (2016). Pengaruh Experiental Marketing dan Bramd ImageTerhadap Kepuasan Pelangan Indihome PT. Telkom Akses Medan. Universitas Medan Area.

Herliza, R., \& Saputri, M. E. (2016). Pengaruh Brand Image Terhadap Kepuasan Pelanggan Studi Pada Zara Di Mall PVJ Bandung. Agustus, 3(2), 1949.

Kartajaya, H., Indrio, B. D., \& Madyani, D. (2004). Marketing in venus. Gramedia Pustaka Utama.

https://books.google.co.id/books?hl=id\&lr=\&id=Iq0_5sHZqPgC\&oi=fnd\&pg=PR1 $0 \& d q=$ Kartajaya,+ H.,+Indrio, + B. + D.,$+\% 26+$ Madyani, + D.+(2004).+\&ots $=$ mEazth Fq10\&sig=vYbMiJMetsFyYyQJWdOQHPqiiEU\&redir_esc $=y \# v=$ onepage $\& q \& f=$ false

Kho, Dessy Prayogo, F. A. (2014). Pengaruh Brand Image Terhadap Kepuasan Pelanggan Dengan Persepsi Nilai Sebagai Variabel Perantara Di TX Travel Surabaya.

Kotler, P., Armstrong, G., Saunders, J., \& Wong, V. (2003). Rinkodaros Principai (Lithuanian Translation of Principles of Marketing: 3rd European Edition). https://www.google.co.id/search?tbm=bks\&hl=id\&q=+Kotler\%2C+P.\%2C+Armst rong $\% 2 \mathrm{C}+\mathrm{G} . \% 2 \mathrm{C}+$ Saunders $\% 2 \mathrm{C}+\mathrm{J} . \% 2 \mathrm{C}+\% 26+\mathrm{W}$ ong $\% 2+\mathrm{V} .+\% 282003 \% 29 .+\mathrm{Ri}$ nkodaros+Principai+\%28Lithuanian+Translation+of+Principles+of+Marketing\%3 A+3rd+European+Edition $\% 29$.

Lullulangi, I. R. (2014). Marketing Terhadap Kepuasan Konsumen ( Studi Kasus: Sop Buah " X" Kota Semarang ).

Maddinsyah, A., et al. (2020). Desain Formulasi Dan Implementasi Bisnis Strategik Dengan Pendekatan Business Model Canvas (BMC) Terintegrasi Kerangka Integrated Performance Management System (IPMS) Pada Koperasi Asperindo. Inovasi, 7(2), 67-76.

Murdani, N. K., Ardani, N. W., \& Prayoga, K. P. (2020). Analisis Pengaruh Kualitas Pelayanan Yang Dimediasi Oleh Perceived Value Terhadap Keputusan Pembelian Ulang Pengguna Kartu Perdana Telkomsel. Jurnal Ilmiah Satyagraha, 3(1), 97-105. ps://doi.org/10.31227/osf.io/tcdmh

Purba, S. (2019). Pengaruh Brand Image Dan Harga Terhadap Kepuasan Pelanggan GrabCar di KOTA MEDAN. 26-32. https://doi.org/10.31227/osf.io/grq7j

Rasyid, N., et al. (2018). Pengaruh Bauran Pemasaran Terhadap Penjualan Pada PT. Nestle Indofood Citarasa Indonesia Di Makassar. SENTRALISASI, 7(2), 11-27.

Rofianto, W., et al. (2021). Cultural Product Branding, Antecedents, And Its Implications: A Study On The Context Of Indonesian Batik. International Journal Of Social, Policy And Law, 2(2), 37-46.

Syarif, K. (2010). Analisis Brand Image Terhadap Kepuasan Pelanggan Survei Konsumen di Kota Bogor. Ilmiah Manajemen, 1, 14-23.

Tjiptono, F. F. dan G. C. (2012). Pemasaran Strategik. ANDI, YOGYAKARTA. http://administrasibisnis.studentjournal.ub.ac.id/index.php/jab/article/view/2124

Wangsi, M. M., et al. (2018). Perlindungan Konsumen Dalam Pelabelan Produk Menurut Ekonomi Islam. Sentralisasi, 7(1), 1-9. 